\title{
Experimental Research on High Temperature Resistance of Modified Lightweight Concrete after Exposure to Elevated Temperatures
}

\author{
Ke-cheng He, ${ }^{1,2}$ Rong-xin Guo, ${ }^{1,2}$ Qian-min Ma, ${ }^{1,2}$ Feng Yan, ${ }^{1,2}$ \\ Zhi-wei Lin, ${ }^{1,2}$ and Yan-Lin Sun ${ }^{3}$ \\ ${ }^{1}$ Faculty of Civil Engineering and Mechanics, Kunming University of Science and Technology, Kunming 650500, China \\ ${ }^{2}$ Key Lab of Yunnan Higher Education Institutes for Mechanical Behavior and Microstructure Design of Advanced Materials, \\ Kunming University of Science and Technology, Kunming 650500, China \\ ${ }^{3}$ Faculty of Chemical Engineering, Kunming University of Science and Technology, Kunming 650500, China
}

Correspondence should be addressed to Rong-xin Guo; guorx@kmust.edu.cn

Received 20 February 2016; Accepted 4 May 2016

Academic Editor: Osman Gencel

Copyright (C) 2016 Ke-cheng He et al. This is an open access article distributed under the Creative Commons Attribution License, which permits unrestricted use, distribution, and reproduction in any medium, provided the original work is properly cited.

\begin{abstract}
In order to improve the spalling resistance of lightweight aggregate concrete at high temperature, two types of modified materials were used to modify clay ceramsite lightweight aggregates by adopting the surface coating modification method. Spalling of the concrete specimens manufactured by using the modified aggregates was observed during a temperature elevation. Mass loss and residual axial compressive strength of the modified concrete specimens after exposure to elevated temperatures were also tested. Concrete specimens consisting of ordinary clay ceramsites and crushed limestone were manufactured as references for comparison. The results showed that the ordinary lightweight concrete specimens and the crushed limestone concrete specimens were completely spalled after exposure to target temperatures above $400^{\circ} \mathrm{C}$ and $1000^{\circ} \mathrm{C}$, respectively, whereas the modified concrete specimens remained intact at $1200^{\circ} \mathrm{C}$, at which approximately $25 \%$ to $38 \%$ of the residual compressive strength was retained. The results indicated that the modified lightweight concrete specimens have exhibited superior mechanical properties and resistance to thermal spalling after exposure to elevated temperatures.
\end{abstract}

\section{Introduction}

Lightweight aggregate concrete types are well known for their advantages of being lightweight and fire-resistant and for having high strength. They have wide use in high-rise buildings and large span bridges. Lightweight aggregates, such as pumice, expanded perlite, and clay ceramsite, which are made by burning, naturally have excellent resistance to high temperature [1]. Thus, it is expected that lightweight aggregate concrete types also have high application potential in chimneys, high temperature furnaces, tunnel fireproof layers, and other fire-resistant constructions. Several references claim that the residual mechanical properties of lightweight aggregate concrete types after exposure to high temperatures of $800^{\circ} \mathrm{C}$ or $1000^{\circ} \mathrm{C}$ were considerably higher than those of ordinary concrete types [2-7].
However, the spalling resistance of lightweight aggregate concrete types often behaves worse than that of ordinary concrete types in a fire due to the ability of lightweight aggregates to act as water reservoirs for evaporable water $[8,9]$. The water in the lightweight aggregates either comes from prewetting of the aggregates, absorption from the fresh concrete, or penetration from the environment [10]. The increased moisture content will lead to both increased pore pressure and an increased temperature gradient during a fire [11]. The higher the moisture content, the higher the spalling probability as the moisture content is greater than a threshold value [12]. Thus, moisture content is the direct factor for the explosive spalling of lightweight aggregate concrete types. If the lightweight aggregate concrete types undergo explosive spalling in fire, their high temperature resistance cannot be fully effective 
TABLE 1: Chemical composition and physical properties of slag cement.

\begin{tabular}{lccccccccc}
\hline \multirow{2}{*}{ Slag cement } & \multicolumn{9}{c}{ Chemical composition: \% } \\
& $\mathrm{SiO}_{2}$ & $\mathrm{CaO}$ & $\mathrm{Al}_{2} \mathrm{O}_{3}$ & $\mathrm{Fe}_{2} \mathrm{O}_{3}$ & $\mathrm{MgO}$ & $\mathrm{SO}_{3}$ & Loss on ignition & Specific gravity & Fineness $(45 \mu \mathrm{m}): \%$ \\
\hline PSA & 17.9 & 54.03 & 5.26 & 3.44 & 1.78 & 1.7 & 4.30 & 3.04 & 11 \\
\hline
\end{tabular}

TABLE 2: Physical properties of coarse aggregates.

\begin{tabular}{lcccc}
\hline Aggregate type & Bulk density $\left(\mathrm{kg} / \mathrm{m}^{3}\right)$ & 1 h water absorption: \% & Cylinder compressive strength $(\mathrm{MPa})$ & Crushing value $(2.5 \mathrm{~mm}): \%$ \\
\hline LS & 1430 & 0.5 & 16.57 & 7.8 \\
LWA & 407 & 14.5 & 3.07 & 47.5 \\
PLWA & 410 & 10.8 & 2.74 & $/$ \\
GLWA & 485 & 9.2 & 3.19 & $/$ \\
\hline
\end{tabular}

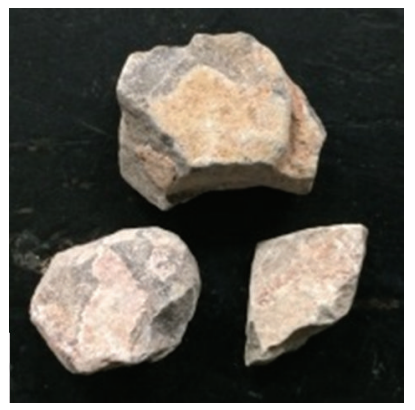

(a) LS

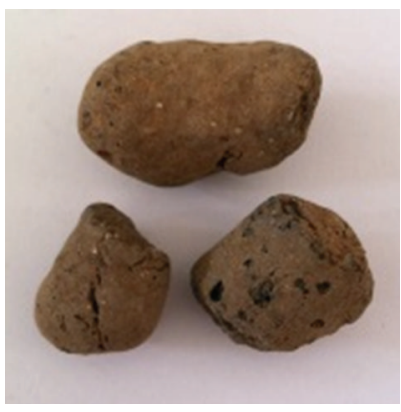

(b) LWA

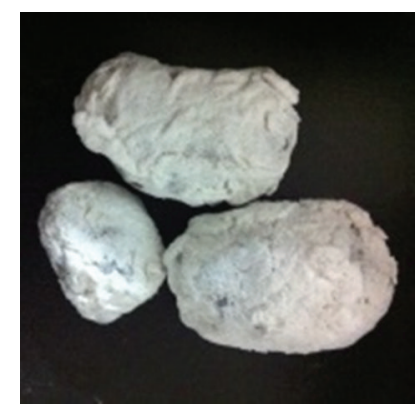

(c) PLWA

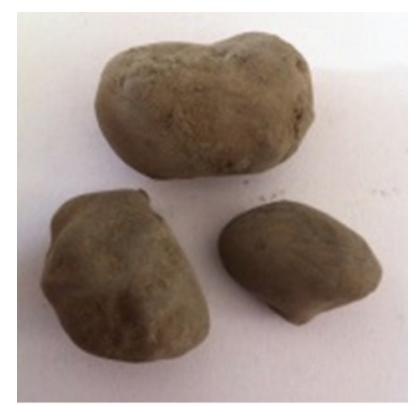

(d) GLWA

FIGURE 1: Different types of coarse aggregates.

in fire protection, thus limiting their application in the fire protection of the building structure.

In light of the unstable high temperature behavior of lightweight aggregate concrete types, in this study, two types of materials were used to modify clay ceramsite. The modified clay ceramsites were used to manufacture lightweight concrete types. The spalling characteristics, mass loss, and residual axial compressive strength of the concrete types after high temperature exposure were examined, and the results were compared to those of concrete types manufactured using normal clay ceramsites and crushed limestone.

\section{Experimental Programmes}

2.1. Raw Materials. The cement used in this study was slag Portland cement (PSA 32.5), provided by Hongshi Cements Ltd., Yiliang, Kunming, Yunnan, China. Its chemical composition and physical properties are given in Table 1. Sand with a fineness modulus of 2.54 was used as fine aggregate. Limestones (LS) and clay ceramsite lightweight aggregates (LWA) were used as coarse aggregates. Both the LS and the LWA had particle size ranges of $5 \mathrm{~mm}$ to $30 \mathrm{~mm}$ and were under continuous grading. Both fine aggregate and coarse aggregates were provided by Chengwei Chemical Building Materials Ltd., Kunming, Yunnan, China.

2.2. Modifications of the Lightweight Aggregates. By adopting the surface coating modification method, two types of materials were used to modify clay ceramsites, that is, modification material I [13] and modification material II [14]. The LS, LWA, modification material I modified lightweight aggregates (PLWA), and modification material II modified lightweight aggregates (GLWA) are shown in Figure 1. The physical properties of the different types of coarse aggregates are given in Table 2 .

2.3. Preparation of Specimens. In order to investigate spalling and the compressive performance of the concrete types after exposure to high temperatures, four concrete mixes were prepared, including normal concrete (NC), lightweight aggregate concrete (LWAC), modification material I modified lightweight aggregate concrete (PLWAC), and modification material II modified lightweight aggregate concrete (GLWAC). A water/binder ratio (W/B) of 0.49 was used, and the total volume of aggregates was kept constant for all four mixes. The W/B used can allow the slump of all the mixes to meet the requirement of S2 [15]. The mix proportions of the concrete specimens are given in Table 3. Before mixing, ovendried LS, LWA, PLWA, and GLWA were presaturated with the water required for their $1 \mathrm{~h}$ water absorption and half of the mixing water. The rest of the mixing water was added during the mixing.

After mixing, concrete types were cast into $100 \mathrm{~mm} \times$ $100 \mathrm{~mm} \times 300 \mathrm{~mm}$ prism mould. After demoulding, concrete specimens were cured in a standard curing room at a temperature of $20 \pm 2^{\circ} \mathrm{C}$ and relative humidity above $95 \%$ for 28 days. Before the exposure to high temperatures, the extra water on the surface of the specimens was wiped off with a damp cloth. 
TABLE 3: Mix proportions.

\begin{tabular}{lccccc}
\hline \multirow{2}{*}{ Mix } & \multicolumn{2}{c}{ Per cubic meter $\left(\mathrm{kg} / \mathrm{m}^{3}\right)$} & 28 d compressive strength (MPa) \\
& Cement & Water & Coarse aggregate & Sand & 28.3 \\
NC & 370 & 180 & 1222 & 658 & 12.6 \\
LWAC & 370 & 180 & 317 & 693 & 12.8 \\
PLWAC & 370 & 180 & 318 & 693 & 13.2 \\
GLWAC & 370 & 180 & 378 & 693 & \\
\hline
\end{tabular}

TABLE 4: Appearance and spalling statistics of the concrete specimens after exposure to elevated temperatures.

\begin{tabular}{|c|c|c|c|c|c|}
\hline \multirow{2}{*}{ Mix } & \multirow{2}{*}{ Temperatures: ${ }^{\circ} \mathrm{C}$} & \multicolumn{3}{|c|}{ Appearance } & \multirow{2}{*}{$\begin{array}{c}\text { Spalling statistics } \\
\qquad R^{(1)}: \%\end{array}$} \\
\hline & & Colors & Cracks & Spalling & \\
\hline \multirow{6}{*}{$\mathrm{NC}$} & 20 & Slight gray & - & - & \multirow{6}{*}{66.7} \\
\hline & 400 & Slight red & Scarce and local & Slight & \\
\hline & 600 & Dark red & A small amount of fine cracks & Medium & \\
\hline & 800 & Cinereous & Long and wide & Medium & \\
\hline & 1000 & Straw white & A large amount of long cracks & Heavy & \\
\hline & 1200 & Slight yellow & Numerous and random & Heavy & \\
\hline \multirow{6}{*}{ LWAC } & 20 & Dark gray & - & - & \multirow{6}{*}{100} \\
\hline & 400 & Dark red & Local microcracks & Slight & \\
\hline & 600 & Slight red & A certain amount of fine cracks & Medium & \\
\hline & 800 & Straw white & Long and wide & Medium & \\
\hline & 1000 & Slight yellow & A large amount of long cracks & Heavy & \\
\hline & 1200 & Soil yellow & Numerous and random & Heavy & \\
\hline \multirow{6}{*}{ PLWAC } & 20 & Dark gray & - & - & \multirow{6}{*}{25} \\
\hline & 400 & Dark red & Scarce and local & - & \\
\hline & 600 & Slight red & Few small shallow cracks & Slight & \\
\hline & 800 & Straw white & A certain amount of fine cracks & Slight & \\
\hline & 1000 & Slight yellow & Long and wide cracks at edges & Medium & \\
\hline & 1200 & Soil yellow & Large amount and located at edges & Medium & \\
\hline \multirow{6}{*}{ GLWAC } & 20 & Dark gray & - & - & \multirow{6}{*}{16.7} \\
\hline & 400 & Dark red & Unclear & - & \\
\hline & 600 & Slight red & Scarce and local & Slight & \\
\hline & 800 & Straw white & A small amount of fine cracks & Slight & \\
\hline & 1000 & Soil yellow & Long and wide cracks at edges & Medium & \\
\hline & 1200 & Brownish Yellow & Large amount and located at edges & Medium & \\
\hline
\end{tabular}

${ }^{(1)} R$ represents the percentage of the specimens spalled when the target temperature was above $400^{\circ} \mathrm{C}$.

2.4. Heating Regime and Test Procedure. Before heating, the specimens in saturated-surface-dry condition were weighed at room temperature. Then, the specimens were placed in an electric furnace under unstressed condition and were heated to $200^{\circ} \mathrm{C}, 400^{\circ} \mathrm{C}, 600^{\circ} \mathrm{C}, 800^{\circ} \mathrm{C}, 1000^{\circ} \mathrm{C}$, and $1200^{\circ} \mathrm{C}$, respectively, with an increasing rate of $10^{\circ} \mathrm{C} / \mathrm{min}$. The elevation of temperature was controlled by a programming instrument with precision of $10^{\circ} \mathrm{C}$. When the target temperatures were achieved, the temperatures were maintained as constant for $3 \mathrm{~h}$ to allow the specimens to reach a thermal steady state. Then, the heated specimens were cooled down slowly to room temperature in the furnace.

During the temperature elevation, the temperatures when spalling occurred were recorded. When the specimens were cooled, they were taken out from the furnace, and any surface changes (i.e., colors, cracks, spalling, etc.) of the specimens due to the high temperatures were recorded as well. The specimens that were still intact (i.e., without spalling) were weighed again followed by crushing for compressive strength test [16].

\section{Results and Discussion}

3.1. Appearance and Spalling. The appearance and spalling statistics of the specimens after exposure to elevated temperatures are reported in Table 4, and the spalling of the specimens after heating is shown in Figure 2. From Table 4 and Figure 2, it can be observed that no spalling occurred for the concrete specimens when the temperature was below $400^{\circ} \mathrm{C}$. When the temperature increased to approximately $450^{\circ} \mathrm{C}$, spalling occurred for the concrete specimens to different extents. Based on a statistical calculation, $66.7 \%$ of the NC specimens 


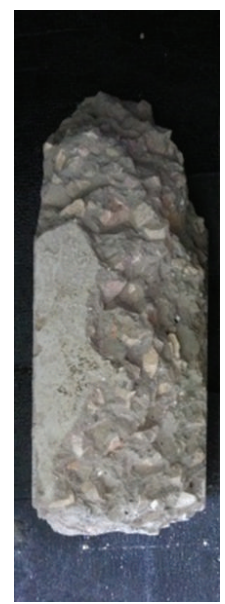

(a) NC

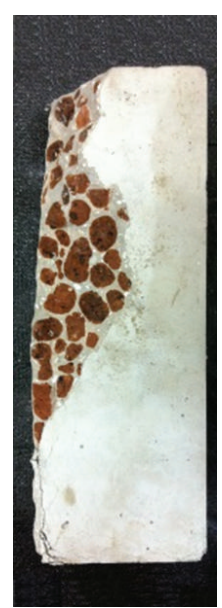

(b) LWAC

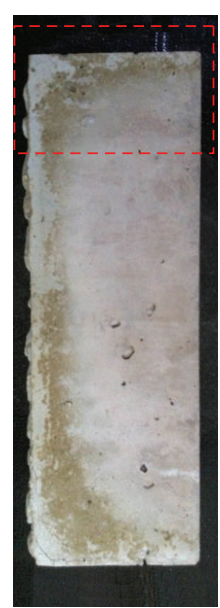

(c) PLWAC

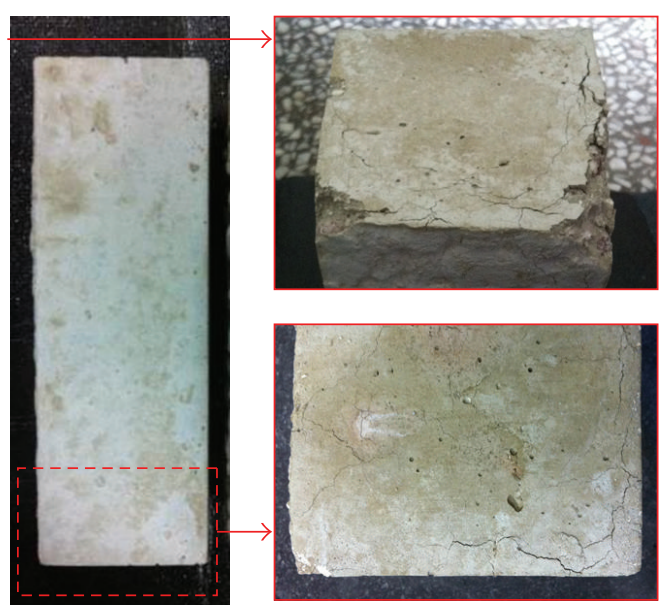

(d) GLWAC

FIgURE 2: Spalling of the concrete specimens.

were spalled when the temperature was above $400^{\circ} \mathrm{C}$; these values for the LWAC, the PLWAC, and the GLWAC specimens were $100 \%, 25 \%$, and $16.7 \%$, respectively. In general, the extent of the damage caused by spalling was most serious for the NC specimens. Spalling mainly occurred at the edges and corners of the specimens, and a considerable volume of the specimens was broken off from the prisms, as shown in Figure 2(a). The spalling mode for the LWAC specimens was tangential damage at the edges of the specimens, with cracks throughout the lightweight aggregates (refer to Figure 2(b)). However, for the PLWAC and the GLWAC concrete specimens, only mild damage was observed at the corners of the specimens, as shown in Figures 2(c) and 2(d).

From Table 4, it can be observed that, due to the prewetting treatment of the lightweight aggregates, the moisture content of the LWAC specimens should be higher than that of the NC ones, and the LWAC specimens were more prone to spall. However, the extent of the damage caused by spalling was smaller for the LWAC specimens. The modifications of the lightweight aggregates greatly reduced the risk of thermal spalling. This may be attributed to the following reasons: (1) the water absorption of the lightweight aggregates was reduced after the modifications (refer to Table 2), as well, leading to a lower moisture content in the concrete specimens, thereby reducing the spalling risk of the modified lightweight concrete types during heating; (2) with the increase of temperature, parts of modification material I could be melted gradually below $400^{\circ} \mathrm{C}$ to form microcracks, connecting the existing capillary pores to provide a channel for the escaping of water vapor, thus reducing the risk of the PLWAC specimens to spall [13]; (3) modification material II exhibited a superior performance at high temperature [14]. Therefore, the aggregates in the GLWAC specimens were enhanced, and the performance of the GLWAC specimens at high temperature was improved.

3.2. Mass Loss. Figure 3 shows the mass loss of the concrete specimens at different temperatures. Due to the spalling of the LWAC specimens after $400^{\circ} \mathrm{C}$ and of the NC specimens after

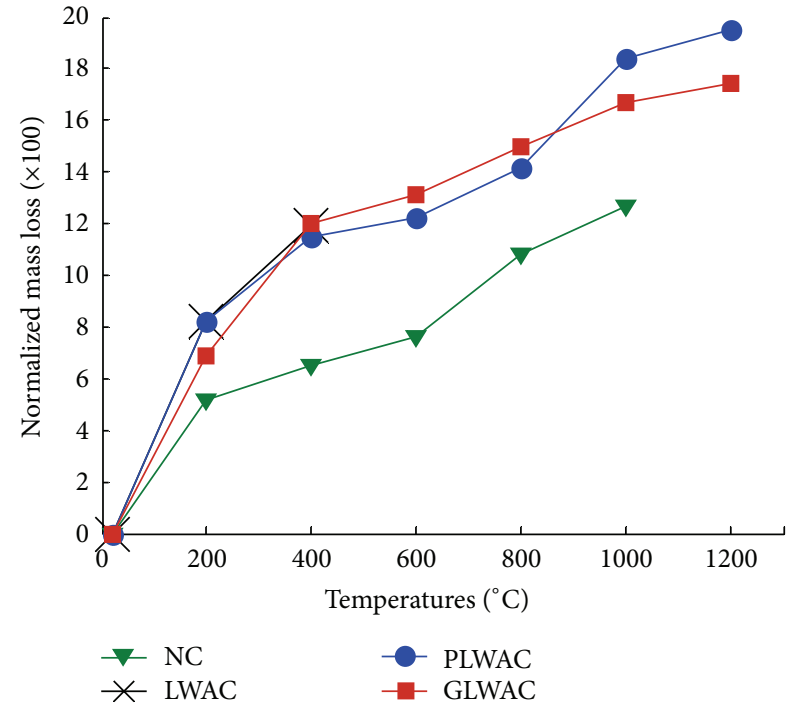

FIgURE 3: Mass loss of the specimens after being heated.

$1000^{\circ} \mathrm{C}$, the mass loss test could not be conducted for these two mixes above these temperatures. Normalized mass loss was calculated by using the following equation:

$$
N_{\mathrm{ml}}=\frac{M_{\mathrm{o}}-M_{t}}{M_{\mathrm{o}}} \times 100,
$$

where $N_{\mathrm{ml}}$ is normalized mass loss; $M_{\mathrm{o}}$ is the original weight at room temperature; $M_{t}$ is the weight at a given temperature.

From Figure 3, it can be observed that the mass losses of the concrete specimens increased to different extents with the increase of temperature. Furthermore, the mass losses of the concrete specimens manufactured using lightweight aggregates were much larger than those of the NC specimens at all the temperatures. Therefore, it is considered that evaporation of water may be the main cause for the mass loss of the concrete specimens as more water could have been introduced into the lightweight concrete types at the beginning of 
TABLE 5: Compressive strength of the concrete specimens after exposure to elevated temperatures.

\begin{tabular}{lccccccc}
\hline \multirow{2}{*}{ Mix } & \multicolumn{7}{c}{ Compressive strength (MPa) } \\
& $20^{\circ} \mathrm{C}$ & $200^{\circ} \mathrm{C}$ & $400^{\circ} \mathrm{C}$ & $600^{\circ} \mathrm{C}$ & $800^{\circ} \mathrm{C}$ & $1000^{\circ} \mathrm{C}$ & $1200^{\circ} \mathrm{C}$ \\
\hline NC & 28.3 & 24.2 & 22.3 & 14.1 & 12.8 & 11.7 & $/$ \\
LWAC & 12.6 & 12.4 & 11.4 & $/$ & $/$ & $/$ & $/$ \\
PLWAC & 12.8 & 11.8 & 10.7 & 8.9 & 8.0 & 5.3 & 3.3 \\
GLWAC & 13.2 & 11.9 & 12.1 & 8.8 & 7.8 & 6.2 & 4.9 \\
\hline
\end{tabular}

the mixing. Due to the modifications of the lightweight aggregates, the water absorption of the PLWA and the GLWA was lower than that of the reference lightweight aggregates (refer to Table 2). Therefore, it was expected that the mass losses of the modified concrete types should be lower than that of the reference lightweight concrete. This was true for the GLWAC specimens. However, the mass loss of the PLWAC specimens was similar to that of the LWAC specimens. The reason for this could be attributed to the melting of modification material I at approximately $200^{\circ} \mathrm{C}-400^{\circ} \mathrm{C}$ to increase the mass loss of the PLWAC specimens. When the temperature increased to approximately $400^{\circ} \mathrm{C}$, although a larger amount of water was involved in the LWAC specimens, the escape of water was much difficult (which may be the reason why the LWAC specimens spalled completely at such temperature). Therefore certain amount of water could be still retained in the specimens, which reduced their mass loss. Compared to the PLWAC specimens, the greater mass losses of the GLWAC specimens at both $600^{\circ} \mathrm{C}$ and $800^{\circ} \mathrm{C}$ may be the result of the solidification of the matrix of modification material II [14]. The higher mass loss of the PLWAC specimens after $800^{\circ} \mathrm{C}$ could be due to the decomposition of modification material I.

3.3. Relative Residual Compressive Strength. Compressive strengths of the concrete specimens at room temperature and the elevated temperatures were reported in Table 5, and the relative results were plotted in Figure 4. The relative residual compressive strength is defined as the ratio between the residual compressive strength at a given temperature and the compressive strength at room temperature. Due to the occurrence of spalling, the compressive strength tests were not conducted for the LWAC specimens after $400^{\circ} \mathrm{C}$ and for the NC specimens after $1000^{\circ} \mathrm{C}$, respectively. From Figure 4, it can be observed that, with the increase of temperature, the residual compressive strength of all the specimens declined. When the temperature was below $400^{\circ} \mathrm{C}$, more than $80 \%$ of the compressive strength was retained for the concrete specimens. When the temperature was above $400^{\circ} \mathrm{C}$, the LWAC specimens spalled completely, and the residual compressive strength for the other concrete specimens began to dramatically decrease. When the temperature further increased to $1200^{\circ} \mathrm{C}$, the NC specimens spalled completely, whereas the PLWAC and the GLWAC specimens still had 25\% and $38 \%$ of the compressive strength retained, respectively.

From Figure 4, it also can be seen that the lightweight concrete specimens always had higher residual compressive strength than the NC specimens after exposure to the elevated temperatures. It is known that the heat conductivity of

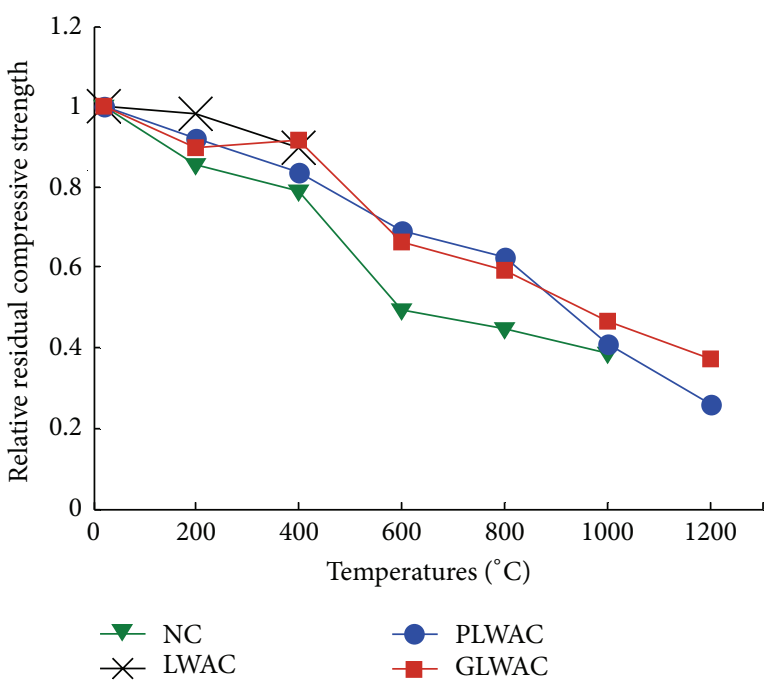

FIgURE 4: Relative residual compressive strength of the concrete specimens after exposure to elevated temperatures.

lightweight aggregates is lower than that of limestone aggregates $[17,18]$. As a result, the temperature rise in lightweight aggregate concrete specimens is at least $15 \%-20 \%$ lower than that of ordinary concrete specimens at high temperature [19]. In this context, compared to the NC specimens, the influence of high temperature on the compressive performance was smaller for the concrete specimens with lightweight aggregates. Furthermore, the materials used to modify the lightweight aggregates may have changed the bonding properties between the cement matrix and the lightweight aggregates. Compared to the reference lightweight concrete specimens, such changing would likely have resulted in different mechanical behavior for the modified concrete specimens. This issue will be explored and detailed in further work.

When the temperature was above approximately $800^{\circ} \mathrm{C}$, the decrease in the compressive strength of the PLWAC specimens was clearer than that of the GLWAC specimens. The reason for this may be attributed to the decomposition of modification material I in the former, whereas the solidification of modification material II at high temperature could allow the strength of the latter to remain at a relatively high level.

\section{Conclusions}

Based on the experimental programme adopted in this study, the following conclusions could be drawn:

(i) The modified lightweight aggregate concrete specimens had much lower risks and extents of spalling after exposure to elevated temperatures. The reasons for this could be attributed to the reduced water absorption, the melting of parts of modification material I in PLWAC specimens, and the improved high temperature resistance of modification material II in GLWAC specimens. 
(ii) After $1200^{\circ} \mathrm{C}$, the PLWAC and the GLWAC specimens still had $26 \%$ and $38 \%$ of the compressive strength retained, respectively, exhibiting superior resistance to high temperature.

\section{Competing Interests}

The authors declare that there are no competing interests regarding the publication of this paper.

\section{Acknowledgments}

The authors gratefully acknowledge the financial supports from the National Science Foundation of China (Grant no. 11562010), the China Postdoctoral Science Foundation (Postdoctoral no. 150039 and Grant no. 2015M572646XB), and the Talent Introduction Project of Kunming University of Science and Technology (Grant no. KKSY201406112).

\section{References}

[1] ACI Committee 213R-14, Guide for Structural Lightweight Aggregate Concrete, chapter 2, American Concrete Institute, 2014.

[2] E. Sancak, Y. Dursun Sari, and O. Simsek, "Effects of elevated temperature on compressive strength and weight loss of the light-weight concrete with silica fume and superplasticizer," Cement and Concrete Composites, vol. 30, no. 8, pp. 715-721, 2008.

[3] H. Tanyildizi and A. Coskun, "Performance of lightweight concrete with silica fume after high temperature," Construction and Building Materials, vol. 22, no. 10, pp. 2124-2129, 2008.

[4] H. Tanyildizi and A. Coskun, "The effect of high temperature on compressive strength and splitting tensile strength of structural lightweight concrete containing fly ash," Construction and Building Materials, vol. 22, no. 11, pp. 2269-2275, 2008.

[5] X. Wu, Z.-M. Wu, J.-J. Zheng, T. Ueda, and S.-H. Yi, "An experimental study on the performance of self-compacting lightweight concrete exposed to elevated temperature," Magazine of Concrete Research, vol. 65, no. 13, pp. 780-786, 2013.

[6] Q. M. Ma, R. X. Guo, Z. M. Zhao, Z. W. Lin, and K. C. $\mathrm{He}$, "Mechanical properties of concrete at high temperaturea review," Construction and Building Materials, vol. 93, pp. 371383, 2015.

[7] F. Koksal, O. Gencel, W. Brostow, and H. E. Hagg Lobland, "Effect of high temperature on mechanical and physical properties of lightweight cement based refractory including expanded vermiculite," Materials Research Innovations, vol. 16, no. 1, pp. 7-13, 2012.

[8] H. Justnes and P. A. Hansen, "Lightweight aggregate concrete for floaters, SP4 hydrocarbon fire resistance. Report 4.1-a theoretical evaluation based on material technology," SINTEF Report STF65 F90009, SINTEF, Trondheim, Norway, 1990.

[9] T. A. Hammer, "Spalling reduction through material design," Trondheim: report 6.2, HSC Phase 3. SINTEF-report nr STF70 A95024, 1995.

[10] J. Lindgård and T. A. Hammer, "Fire resistance of structural lightweight aggregate concrete a literature review survey with focus on spalling, supplementary papers," in Proceedings of 4th CANMET/ACI/JCI International Conference on Recent Advances in Concrete Technology, pp. 25-39, Tokushima, Japan, 1998.
[11] W. J. Copier, "The spalling of normal and lightweight concrete exposed to fire," in Proceedings published in Fire Safety of Concrete Structures, pp. 219-236, Fall Convention of the American Concrete Institute, Detroit MI, USA, 1983.

[12] S. Y. N. Chan, G.-F. Peng, and M. Anson, "Fire behavior of high-performance concrete made with silica fume at various moisture contents," ACI Materials Journal, vol. 96, no. 3, pp. 405-411, 1999.

[13] R. X. Guo, Q. M. Ma, Y. L. Sun et al., "Coated light-weight aggregate, and preparation method and application thereof," China, Patent CN104529212A, patent pending, April 2015.

[14] R. X. Guo, Q. M. Ma, Y. L. Sun et al., "Coated light-weight aggregate, and preparation method and application thereof," China, Patent CN104556767A, patent pending, April 2015.

[15] China Standard, JBJ 51 Technical Specification for Lightweight Aggregate Concrete, China Standard, Beijing, China, 2002.

[16] China Standard, GBJ50081 Method for Testing Mechanical Properties of Normal Concrete, China Standard, Beijing, China, 2002.

[17] FIP Manual of Lightweight Aggregate Concrete, Kapitlene 5.8.2 og 6.3, Surrey University Press, London, UK, 2nd edition, 1983.

[18] R. Felicetti, P. G. Gambarova, and P. Bamonte, "Thermal and mechanical properties of light-weight concrete exposed to high temperature," Fire and Materials, vol. 37, no. 3, pp. 200-216, 2013.

[19] R. I. Zwiers and B. J. Morgan, "Performance of concrete members subjected to large hydrocarbon pool fires," PCI Journal, vol. 34, no. 1, pp. 120-136, 1989. 

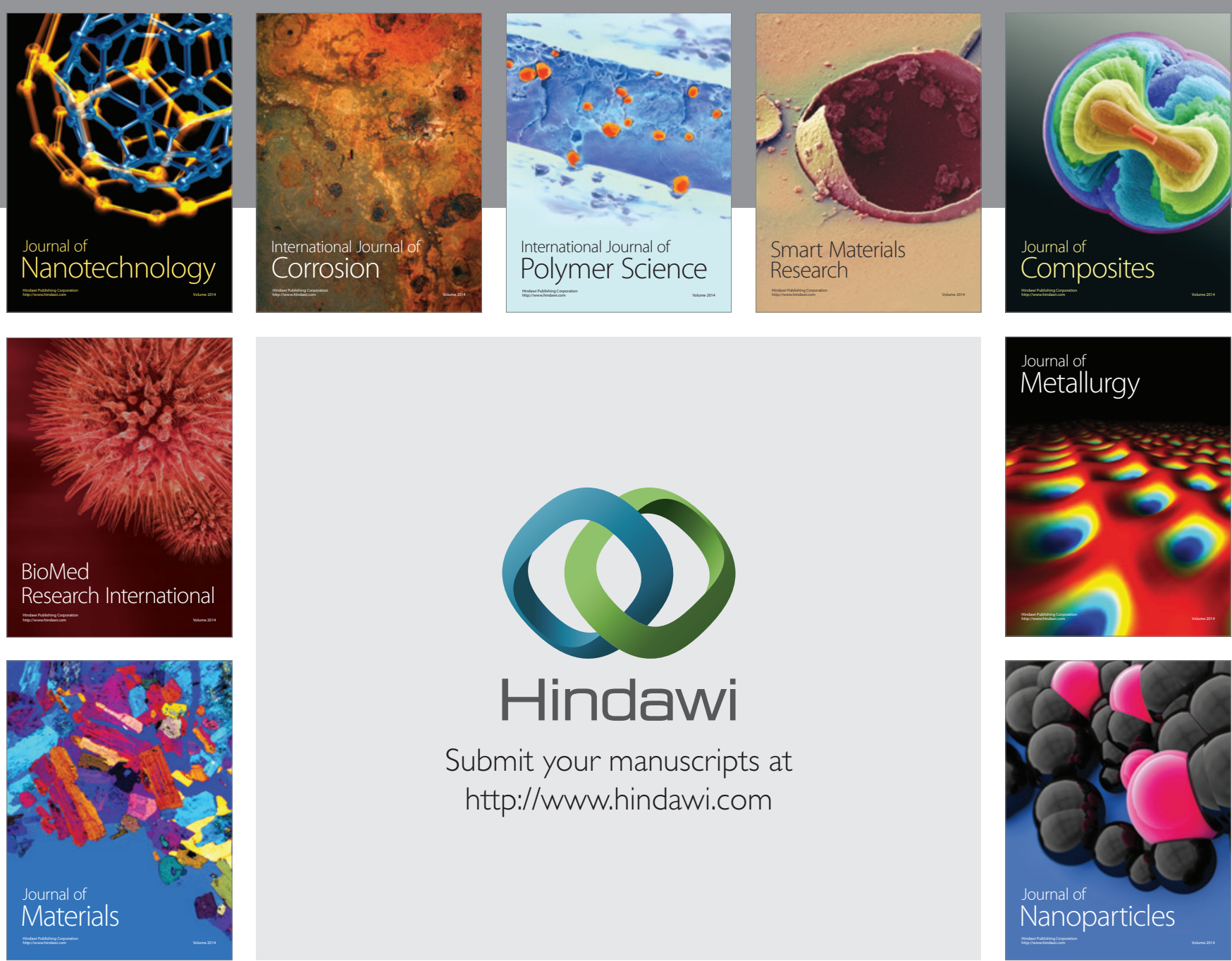

\section{Hindawi}

Submit your manuscripts at

http://www.hindawi.com

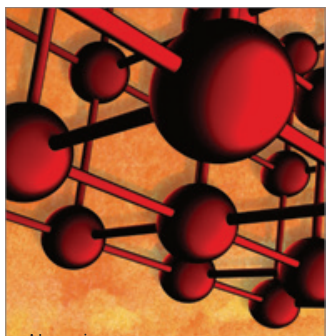

Materials Science and Engineering
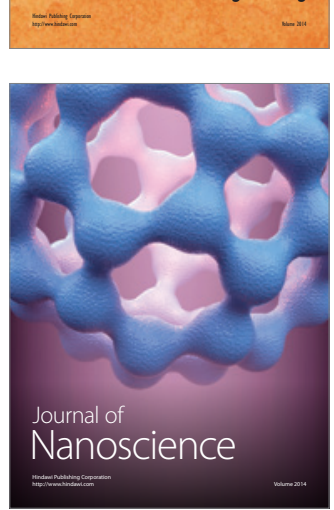
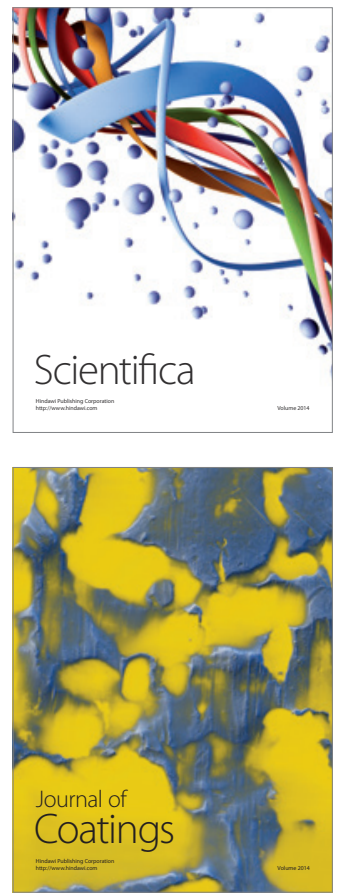
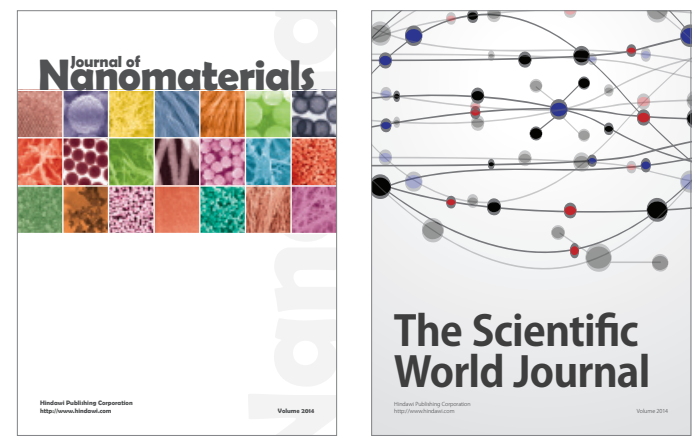

The Scientific World Journal
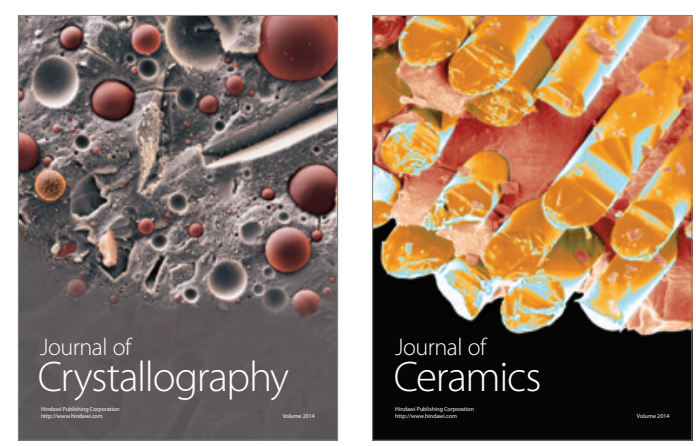
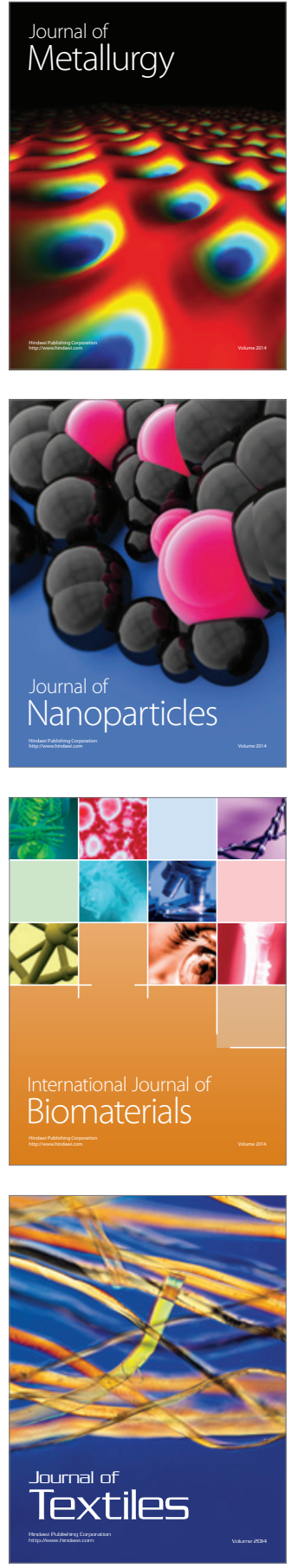